ISSN: $1130-3743$

\title{
LA FORMACIÓN DE CIUDADANOS CRÍTICOS. UNA APUESTA POR LOS MEDIOS
}

\author{
Training of critical citizens. A bet for means
}

\author{
La formation des citoyens critiques. Un pari \\ pour les media
}

Margarita GONZÁLEZ SÁNCHEZ y José Manuel MUÑOZ RODRÍGUEZ Universidad de Salamanca. Facultad de Educación. Departamento de Teoría e Historia de la Educación. Paseo de Canalejas, 169. 37008 Salamanca.

Correo-e:mgsa@usal.es; pepema@usal.es

Fecha de aceptación definitiva: marzo de 2003

BIBLID [(1130-3743) 14, 2002, 207-233]

RESUMEN

Los medios de comunicación requieren de una constante reflexión en torno al papel que desempeñan en la sociedad actual. En este artículo se parte de la idea de abrir el mundo cerrado del aula al entorno, rico en posibilidades educativas. Pensamos que hemos de comprender desde el entorno exterior de los centros los mensajes que emiten los medios de comunicación para así asumir el reto formativo que nos plantean, principalmente en la edad en la que los individuos, si bien no manipulan esos medios, sí reciben su información.

En esta perspectiva, la cuestión radica no tanto en hacer uno u otro uso de los medios, ni incluso disponer de un tamiz educativo que filtre el acceso a ellos, sino más bien en interpretar el lenguaje significativo y comunicacional de los medios para así poder encontrar las claves formativas de lo que debe ser una educación autónoma y crítica en los medios. Ello supone la necesidad de potenciar y desarrollar una formación en medios, formando personas reflexivas y críticas ante ellos; es necesario enseñar a interpretar y actuar con el conocimiento, a saber manejar de forma crítica y creativa las fuentes de información y el mejor instrumento en este 
sentido es la educación, que debe estar en permanente diálogo con los medios si quiere hacer de los ciudadanos del siglo Xxi sujetos críticos, autónomos y reflexivos ante los medios.

Palabras clave: medios de comunicación, procesos de formación, pensamiento crítico, sociedad de la información y de la comunicación.

\section{SUMMARY}

The communication media require a constant reflection around the role that they play in current society. In this article it is started from the idea of opening the closed world of the classroom to the outside environment, rich in educational possibilities. We think that we have to understand from the foreign environment the messages issued from the media, in order to assume the formative challenge that they put forward to us, principally in the age in which the individuals, even though they do not handle those media, receive its information.

In this perspective, the question lives not so much in making one or other use of the media, neither including having an educational sieve than it filters access to them, but rather in interpreting the significant and communication language of the media. And in this way we will to be able to find the training keys to reach an independent and critical education on the media's world. It means the need to promote and develop training in media, in order to train reflexive and critical people face to it. It is necessary to teach to interpret and act with the knowledge. It is necessary, as well, to teach on how handle in a critical and creative way the sources of information. And the best instrument in this sense is the education, which must be in permanent dialogue with the media if it wants to do critical, independent and reflexive subject citizens of the $21^{\text {st }}$ century confronted to the communication media.

Key words: communication media, processes of training, critical thought, society of the information and communication.

\section{SOMMAIRE}

Les moyens de communication demandent une constante réflexion quant à son rôle dans la société actuelle. Cet article part de l'idée d'ouvrir le monde fermé de la classe vers l'extérieur, riche en possibilités éducatives. Nous pensons qu'il faut comprendre depuis l'environnement extérieur de l'école les messages émis par les moyens de communication; de cette façon nous pourrons mieux relever le défi dans le domaine de la formation, surtout à l'âge où les individus - même s'ils n'utilisent pas ces moyens- reçoivent toute l'information.

Dans cette optique, la question clé ne se trouve pas dans l'utilisation des ces moyens ni dans l'établissement d'un filtre éducatif pour y accéder. La vraie question est plutôt de savoir bien interpréter le langage significatif de ces moyens de communication, dans le but d'être capable d'identifier les solutions quant aux formations propres à une éducation autonome et critique. Cela implique d'encourager et de développer une formation dans le domaine des moyens de communication, tout en formant des personnes à faire preuve de réflexion critique à cet égard. Il faut dès lors 
apprendre à interpréter et agir en connaissance de cause, ainsi qu'à utiliser les sources d'information de manière critique et créative. Et la meilleure façon d'atteindre cet objectif est l'éducation, qui doit être en dialogue constant avec ces moyens de communication si l'on veut faire des citoyens du XXI siècle des sujets critiques et autonomes.

Mots clef: moyens de communication, mécanismes de formation, pensée critique, société de l'information et de la communication.

A estas alturas no hay ninguna duda acerca del creciente impacto de los medios de comunicación en la sociedad actual. Puede parecer innecesario el hecho de seguir insistiendo en la actualidad en la influencia e importancia de los medios por resultar reiterativo; no en vano, se ha propuesto el nombre de sociedad de la información y la comunicación, poniéndose de esta manera de relieve hasta qué punto la información y la comunicación configuran cada día nuestras vidas, suponiendo a su vez un interrogante al mundo educativo sobre el modo y manera en que desarrolla los mecanismos de formación en esos medios que diariamente nos interpelan. Nuestro planeta se ha convertido gracias a los medios en la aldea global que se anunciaba décadas atrás por McLuham que debemos estar revisando constantemente, pues el discurrir e influir de los medios es incesante, perseverante y creciente.

Es más, en una sociedad seducida por la innovación y la incorporación de las nuevas tecnologías, marcada por los nuevos medios y las infopistas, la lógica imperante parece señalar que todo lo anterior resulta caduco, pudiendo catalogarse el discurso y la reflexión sobre los medios como algo atávico y trasnochado. Muy al contrario, en este ritmo precipitado con que se producen y aceptan las nuevas tecnologías no se trata de que un medio desplace a otro, sino justamente de lograr la complementariedad; reformular esta complementariedad resulta una tarea necesaria. Situados en el marco del proceso de enseñanza-aprendizaje ha de valorarse que la sofisticación tecnológica no garantiza la efectividad del proceso de enseñanza, por lo que se puede afirmar que ningún medio promueve el aprendizaje mejor que otro, sino que dependerá de cada circunstancia, tipo de tarea, aptitudes del aprendiz, objetivos curriculares, etc.

En nuestra reflexión partimos de la idea de abrir el mundo cerrado del aula al entorno, rico en posibilidades educativas, al que los alumnos están expuestos. Aunque los medios existen desde hace tiempo, la escuela ha mantenido una postura polarizada en sus intereses particulares, dejando entrar a los medios, pero sin escucharlos, sin analizarlos, sin destripar el engranaje semiótico y comunicativo que se encuentra en su interior para así descubrir las claves de formación de los sujetos que, quieran o no quieran, se ven influenciados y marcados por las señales, imágenes y signos que emiten esos medios. Hemos de comprender desde el entorno exterior de los centros los mensajes que emiten los medios para así asumir el reto formativo que nos plantean, principalmente en las edades en las que los individuos, 
si bien no manipulan asiduamente esos medios, sí reciben descaradamente su información.

En la línea del discurso del informe de Delors (1996) para la Unesco, nuestra visión de cómo debería ser la educación para el siglo XXI gravita en torno a los cuatro pilares que enuncia el citado informe: aprender a ser, aprender a hacer, aprender a conocer y aprender a vivir juntos. Pero los sistemas educativos actuales no van en la dirección apuntada por este informe, sino que más bien se siguen centrando en la adquisición de conocimientos académicos, en los dos pilares de aprender a hacer y aprender a conocer, lo que evidencia pues que en muchos centros escolares, en general, más que aprender a conocer, lo que se aprende es a memorizar dogmáticamente, a repetir acríticamente, a almacenar conocimientos académicos. Esto nos plantea la falta de funcionalidad de la que carecen las áreas disciplinares en la mayoría de los casos.

Es necesario enseñar al alumno a interpretar y a actuar con el conocimiento, a emplearlo en su vida activa a lo largo de toda la vida; hay que enseñarle a saber manejar de forma crítica y creativa las fuentes de información. En este contexto contemplamos y encuadramos la educación en los medios de comunicación, algo que se fomenta con un tema transversal ${ }^{1}$, pero que necesita ir más allá y ser analizado, no tanto como herramienta y utensilio de trabajo, sino como agente socializador y formativo de la persona, que influye mayoritariamente en su desarrollo, y que demanda al mundo de la educación nuevas reflexiones que posibiliten encontrar las vías de formación que hemos de seguir para hacer del individuo, principalmente en sus edades tempranas, un sujeto crítico ante el mundo mediático con el que nos ha tocado en suerte convivir.

\section{LA INCERTIDUMBRE DE LA ESCUELA ANTE LOS MEDIOS DE COMUNICACIÓN}

Estamos inmersos dentro de la denominada sociedad de la información, una sociedad en la que los avances emergen a gran velocidad y donde los medios de comunicación, considerados como uno de los principales agentes de esta realidad social, desarrollan una gran importancia y trascendencia, pues participan en el proceso de globalización de la sociedad y, a su vez, desempeñan un papel relevante en la vida diaria de los ciudadanos ejerciendo un fuerte poder de transformación en la sociedad. Es decir, partimos de un mundo paradójico en cuanto que los medios, a la vez que se ubican dentro de la realidad tecnificada y mundializada perteneciente al flujo de los espacios globales, se entremezclan en el discurrir diario de los individuos, formando parte del "mundo de la vida" de cada uno de nosotros,

1. No debemos pues desaprovechar la oportunidad que ofrece la LOGSE que ha optado por que pase a integrar los contenidos de algunas áreas de conocimiento o disciplinas ya existentes e integrar definitivamente, tal vez de forma explícita, la enseñanza de los medios de comunicación al trabajo educativo (PÉrEZ, 1995). 
a niveles locales, entremezclándose en los procesos de territorialización de los individuos.

Es lógico pensar que la escuela no debe de pasar desapercibida ante esta realidad y su cometido es incorporar los medios a sus procesos educativos como una fuente de recursos y como un método y soporte para transmitir sus informaciones y sus conocimientos. No tenemos más que hacer el ejercicio mental de pensar en las causas que justifican una educación en los medios para comprobar la necesidad que existe de tal tarea. De este modo, siguiendo el planteamiento expuesto por Masterman (1993) podemos señalar, entre otros, los siguientes motivos que justifican una educación en los medios de comunicación:

- El elevado índice de consumo de medios y la saturación de éstos en la sociedad contemporánea.

- La importancia ideológica de los medios y su influencia como empresas de conciencia.

- El aumento de la manipulación, fabricación de la información y su propagación por los medios.

- La ascendiente penetración de los medios en los procesos democráticos fundamentales.

- La creciente importancia de la comunicación en la información audiovisual en todas las áreas.

- La trascendencia de educar a los alumnos para que hagan frente a las exigencias del futuro.

- Y el vertiginoso incremento de las presiones nacionales e internacionales para privatizar la información.

En convivencia con estos motivos educacionales, esta escuela de hoy, a pesar de todo, vive momentos de incertidumbre, de cierta esquizofrenia cultural en su práctica educativa; de un lado, se encuentra apartada de la vida, de la sociedad y de la actualidad en más ocasiones de las deseadas, y el problema se agrava cuando se crea la distancia entre la escuela y lo que hay que saber para comprender el mundo actual. En palabras de Jacquinot $(2003,43)$

una (la escuela) mira hacia el pasado (el patrimonio), los otros (los medios) se interesan solamente por el presente. Una (la escuela), descansa en la lógica de la razón; los otros (los medios), en la sorpresa del hecho y el impacto de lo emocional. Una (la escuela) ignora (iignoraba?) la lógica económica; los otros (los medios) sólo funcionan apoyándose en ella... El estudio de los medios valoriza las subjetividades, cuando la objetividad subyace en todas las disciplinas que se enseña en la escuela.

Pero, de otro lado, la escuela de hoy busca incesantemente recursos en la sociedad en la que está insertada para que el proceso de enseñanza-aprendizaje no esté desconectado de ésta, sino en plena conexión con la realidad en la que se ubica. La escuela busca atender las demandas de la sociedad, adecuarse a los 
nuevos tiempos, con lo cual no puede desatender a los medios, ya que ellos le posibilitan un acercamiento y puesta al día. La oposición entre medio y escuela no está tan delimitada, pues existen puntos en común importantes ya que lo que se aprende en la escuela puede ayudar a comprender los mensajes de los medios y viceversa.

Se pone pues de manifiesto la necesidad de utilizar los medios de comunicación social más allá de lo que ha venido siendo la práctica habitual, definida bien por el desconocimiento, por parte de algunos sectores educativos, de la influencia de los medios manteniendo la tradición escolar distanciada de la realidad social; bien por la introducción de los medios en la escuela pero con objetivos pedagógicos tradicionales como puede ser el hecho de aprender vocabulario o gramática, música o geografía; bien, integrando los medios en conversaciones superficiales como si la escuela fuera exclusivamente foro de debate de la actualidad mediática sin ningún tipo de exigencia formativa ni de construcción de valores, actitudes y conocimientos $^{2}$.

Más allá de estos planteamientos, la escuela tiene que hacerse eco del enorme impacto que tienen los medios en la sociedad actual y concebirlos no sólo como una ayuda en la nada fácil tarea de enseñar, sino más aún como referente que indica las bases sólidas sobre las que hemos de edificar e implementar los procesos primarios de formación de las personas. La escuela debe aprender a utilizar un modelo comunicativo nuevo que haga referencia a los nuevos y viejos medios de comunicación, a sus imágenes, a sus significados y, sobre todo, a su lenguaje y a su proceso comunicativo pues, en última instancia, los procesos comunicativos encuentran explicación en las raíces de los procesos educacionales; o, en otras palabras, el problema de la comunicación hunde sus raíces en los fenómenos educativos de las personas. Como indica Dewey $(1998,19)$ "lo que la nutrición y la reproducción son a la vida fisiológica, es la educación a la vida social. Esta educación consiste primordialmente en la transmisión mediante la comunicación".

La situación planteada es sencilla: entre los diferentes espacios donde se desarrolla la vida de los niños, la casa y el centro de enseñanza le proporcionan experiencias directas pero, junto a estos dos mundos, tenemos además los medios de comunicación, en ese momento a su alcance, que lo que le proporcionan es una realidad mediatizada a través de los ojos de otra persona. De esta manera, cuando el alumno llega a la escuela va con un bagaje de experiencias personales y sociales que ha adquirido en su entorno familiar y próximo y en un medio que está dominado por la cultura audiovisual y comunicacional. Esta realidad del alumno, que ha cambiado, debe ser contemplada por la escuela, pues estamos ante un alumno que ha modificado sus hábitos y su dinámica relacional por la presencia

2. En términos parecidos lo expresa Fontcuberta $(1993,51)$ arguyendo que "la relación de los medios de comunicación y la enseñanza, suele moverse entre dos polos: la calificación de los medios como perversos por sí mismos o la aceptación ciega y acrítica del modo de producción comunicativo. Ello supone la adopción de una actitud defensiva por parte de la escuela o el uso de los medios, sin introducir ningún tipo de filtro o pauta crítica". 
en los hogares de algunos medios como por ejemplo la televisión. "Una realidad no sólo de medios sino de contenidos de comunicación de masas que inciden de forma manifiesta en la mayoría de los ciudadanos y muy especialmente en los menores de edad, los que están en proceso de formación" (Ferrés, 1996, 458) y que debe ser contemplada por la escuela, desde donde se debe facilitar la posibilidad de convertirse en un sujeto crítico ante la gran cantidad de información en la que vive inmerso.

Son muy diversas y heterogéneas las interpretaciones que se hacen y que se pueden hacer sobre los mensajes que dan cuerpo a las transacciones informativocomunicativas que acontecen en los procesos de interrelación que se dan entre los niños y los medios de comunicación. Concretamente, siguiendo el modelo que presenta Aparici (1996) podemos interpretarlos:

- Como espejos de la realidad: los medios son unos recursos que captan la realidad y la reproducen tal cual es. La teoría de los espejos no pone en cuestionamiento ninguna de las representaciones que realizan los medios, porque éstas no son ni más ni menos que atributos de la propia realidad, captada fidedignamente por el medio.

- Como ventanas al mundo: a través de los medios se puede tener un conocimiento objetivo del mundo y de la gente, así como de su forma de pensar y valorar las cosas.

- Como construcciones de la realidad: los medios realizan construcciones de la realidad que son formas de representación que dependen de la empresa, su ideología y, los intereses económicos, sociales o políticos de la industria de los medios.

Ahora bien, la realidad, las informaciones, los contenidos comunicacionales se mediatizan por los códigos de representación de cada medio. Lo difícil para la escuela, dentro del marco incierto en el que se mueve, es no sólo llegar a distinguir qué sistema de símbolos es el más adecuado, qué medio es el que se considera mejor capacitado para representar los contenidos, pues unos sistemas simbólicos, en tanto que conjuntos articulados de significantes que hacen referencia a contenidos, están más indicados que otros para la transmisión de una u otra información, de uno u otro contenido (Cabero, 1995), sino más aún, qué principios y procesos formativos debe desarrollar de modo que el sujeto sea capaz de asumir críticamente las información que recibe de los medios, a tenor, básicamente, de que "los medios son importantes moldeadores de nuestras percepciones e ideas, son Empresas de Concienciación que no sólo proporcionan información acerca del mundo, sino maneras de verlo y entenderlo" (Masterman, 1993, 18) ${ }^{3}$.

3. No obstante, hemos de acuñar igualmente que si la escuela se encuentra en momentos inciertos, no es menos cierto que los medios padecen cierta indefinición ya que hablamos normalmente de los medios de comunicación como un conjunto indiferenciado, aunque sólo sea porque cada medio 
Debemos pues cuestionarnos. ¿Qué formación es la que requiere el individuo para enfrentarse a los distintos efectos generados como efectos de los medios? ¿Qué contenidos educativos deben dar cuerpo a los procesos formativos de cara a que los sujetos puedan convivir y relacionarse con ellos de forma crítica? De entrada, el discurso distingue entre una doble dimensión: educar en los medios y educar con los medios. Dos dimensiones diversificadas pero que pueden y deben acabar por confluir. Se trata de integrar los medios en la educación tanto como materia de estudio, como recurso para el proceso de enseñanza-aprendizaje. Por un lado, hay pues que enseñar a leer un periódico, un cómic, a escuchar la radio, a ver la televisión, el cine, a navegar por Internet. Hay que ofrecer metodologías y pautas para el aprendizaje del análisis de los diversos discursos en los diferentes medios. Y, por otro lado, hay que incorporar a las aulas para optimizar (motivar, ilustrar, ejemplificar...) el proceso de enseñanza-aprendizaje las noticias de los informativos, los spots publicitarios, secuencias de películas, capítulos de series, documentales, recortes y suplementos de prensa, etc.

Entre tanto, conscientes de que los medios son una fuente permanente de información con una importante dimensión educadora, la educación, la escuela, debe desarrollar y buscar la capacitación de la persona para aprovechar educativamente esa vía y fuente no convencional, continua y progresiva de información que constituyen los medios y capacitar al sujeto para una opción responsable entre las múltiples alternativas ofrecidas.

Actualmente, estamos ante un período en donde los acontecimientos, los avatares y fenómenos diarios vienen siendo calificados como complejos, producto de múltiples roturas sociales y culturales, que conllevan desajustes personales que pasan a formar parte de la denominada complejidad creciente en la que estamos inmersos, lo cual ha supuesto un despertar de una corriente de pensamiento en torno a la complejidad (Colom, 2002; Morin, 2002). Ello no pasa desapercibido en el campo de la educación en relación a los medios de comunicación, visto el desarrollo que se ha producido y la abundancia de información que el ciudadano recibe a través de los diferentes medios de comunicación social.

La escuela tiene que revisar de forma permanente su sentido, debe poner en tela de juicio su quehacer. Porque todo cambia. Y acaso, en la sociedad de la información, debe hacer menos hincapié en transmitir conocimientos que en ofrecer criterios para discriminar el conocimiento que el alumnado recibe a través de miles de fuentes que le ofrecen una información sesgada, vulgar (no científica) y

está limitado por sus propias características y cada medio tiene su propio modo de presentarnos la información; es decir, cáda medio tiene características propias que determinan su estructura y su efecto en los usuarios. "Hay que tener en cuenta cuando se clasifica el contenido de los medios que ninguno de sus productos es inherentemente objetivo... desde el momento en que todos los medios proporcionan una visión elaborada de la realidad” (TYNER, 1995, 28). 
adulterada... No basta saber, hay que utilizar el saber con sentido liberador y solidario (Santos Guerra, 2002, 30).

Por tanto, como ya se reconocía en el Libro Blanco de la Reforma (MEC, 1989), la necesidad de dotar a los ciudadanos de una formación básica en materia de comunicación es una cuestión inaplazable. Sólo así llegaremos a concebir las estrategias e intervenciones educativas como estrategias comunicativas, fomentando la comprensión de las situaciones de interacción entre los individuos y los medios como contextos de acción educativa. El estudio de estas posibilidades pedagógicas comprende parte de los procesos formativos, concibiendo la pedagogía como posibilitadora de un sistema de reglas y planes de actuación, creadora de circunstancias comunicacionales entre los sujetos y los medios, que facilitan y vehiculan los procesos formativos que configuran el proyecto de una educación en los medios como campo de estudio que incide en todo aquello que sucede entre los ciudadanos y los medios de comunicación.

\section{El PAPEL DE LOS MEDIOS DE COMUNICACIÓN}

Siendo consecuentes con el planteamiento que hemos mantenido en el epígrafe anterior, estamos abocados a la reflexión, casi diaria, del papel que juegan los medios en nuestras vidas, en nuestras relaciones y acciones diarias pues, toda incertidumbre pedagógica, que conlleva en muchos casos posicionamientos de encrucijada, necesita, al menos, tiempos y espacios de reflexión sobre el papel, funciones y efectos, que tiene los medios como generadores de esa incertidumbre, pues existen multitud de aspectos susceptibles de análisis desde el punto de vista educativo tales como, por ejemplo, el hecho de comprobar si es necesario hacer reflexionar a los niños sobre la influencia, sobre los valores y contravalores que transmiten los distintos medios, sobre la función socializadora que cumplen, sobre el control que ejercen y al que someten, sobre la heterogénea información que transmiten, sobre los mecanismos que ponen en juego. Tomando palabras del periodista Joaquín Fernández:

Estamos obsesionados por los medios de comunicación y esa obsesión nos impide en cierto modo una aproximación inteligente a ellos. Ésta sí que es una tarea pedagógica importante. Hoy más que nunca, tenemos que enseñar en las escuelas qué son los medios, cómo funcionan, cuáles son sus caprichosos criterios para seleccionar la actualidad; tenemos que analizar sus influencias, sus intereses, sus juegos sucios disimulados siempre bajo el pretexto del interés general o de la esclavitud de las audiencias. Y, por encima de todo, su temible poder (Fernández, 1998, 304).

Hubo un tiempo en que los medios eran objeto de análisis y estudio en las escuelas y centros educativos - algún medio-; luego se han ido generando otras demandas en relación con la atención a determinados contenidos o, incluso, con los métodos de elaboración de la información. Finalmente, se llega incluso a pedir, 
como indica el autor anteriormente citado, "auxilio pedagógico" a esos medios y hasta queremos que se hagan eco de nuestras experiencias. Como muy bien señala Fontcuberta (1992), la misión de los medios de comunicación en un principio fue simplemente la de transmitir información, pero con el tiempo empezaron a desarrollar otras funciones hasta llegar al momento actual en el que además de informar, forman y entretienen. Todo ello nos ha hecho olvidar el punto de partida. Hemos de volver al análisis y la reflexión sobre las funciones y efectos de los medios, como núcleo de inteligibilidad de la acción formativa en los medios.

Son numerosas y diversas las funciones que se le asignan a los medios, bien de corte personal, social, comunicativo o informativo. No tenemos más que revisar las señaladas por Parcerisa (1996), para comprobar la amalgama de posibilidades existentes, a saber:

- Innovadora, al crear con su incorporación nuevos entornos y situaciones.

- Motivadora, en tanto que facilita la captación de la atención de los alumnos.

- Estructuradora de la realidad al presentarla de una forma específica u otra al ser elemento mediador y disponer de diferentes sistemas simbólicos.

- Configuradora del tipo de relación que el alumno llega a establecer con los contenidos del aprendizaje.

- Controladora de los contenidos a enseñar.

- Solicitadora, al actuar el material como guía metodológica organizando la acción formativa y comunicativa.

- Formativa, pues ayuda a la adquisición de información y a la formación de habilidades y actitudes.

- De depósito del método y de la profesionalidad.

- De producto de consumo con un vigencia temporal específica ${ }^{4}$.

Y, por lo que respecta a los efectos, hemos de decir que son igualmente múltiples, fiel reflejo de la influencia que los medios de comunicación están teniendo en nuestra sociedad. En un intento de síntesis, siguiendo el planteamiento expuesto por Fleur (1993) podemos dividirlos en tres:

- Efectos cognitivos: que implican la creación y resolución de la ambigüedad, la formación de actitudes, la fijación de agenda, ampliación, valores, etc.

- Efectos afectivos: tales como la desensibilización, miedo y ansiedad, moral y alineación.

- Efectos conductuales: como puede ser la activación y desactivación de los individuos.

Pues bien, ante este marco general de referencia, cabe señalar brevemente el papel de los medios desde diversos frentes. Por un lado, desde un punto de vista

4. Podemos encontrar otras relaciones de usos y funciones en Zabalza (1987, 197-199), Cebrián de la SeRna $(1992,123-124)$, GonzÁlez SOTO $(1998,17)$. 
político y social, comprobamos cómo uno de los aspectos y efectos más preocupantes y que debe de poner en situación de cierta alerta al mundo de la educación es el que hace referencia al poder y control de los medios de comunicación. La información siempre esta marcada por la ideología del poder, desde donde se lanza información interesada. Son los grandes árbitros de la conducta económica, política, ética y psicológica de la sociedad. Aspecto éste relevante como el control que ejercen los medios sobre los usuarios o mejor dicho sobre la información. Controlan lo que las personas oyen, leen y ven, lo que sin ninguna duda supone un gran poder en cualquier sociedad.

No es accidental por eso que sean las emisoras de radio o televisión y las redacciones de los periódicos el primer objetivo de un ejercito o grupo vencedor, porque controlando los canales de comunicación pueden controlar al pueblo (Tyner, 1995, 26-27).

Aunque un ideal importante sea la objetividad y la ecuanimidad que se plantean los editores, al menos en la información y representación de los acontecimientos, cualquiera que trabaje con los medios de comunicación sabe que el mensaje que a través de ellos se nos transmite va cargado de informaciones, de ideas y de valores ideológicos inherentes. Valores, subjetividad, ideología que se da siempre en los medios y que, a la hora de trabajar con ellos, hemos de tener presente con el objetivo de enseñar a los alumnos a identificarlos, a la vez que les mostramos las técnicas discursivas para cuestionarlos y evaluarlos, fomentando así la independencia de pensamiento y en definitiva una autonomía crítica. En este entorno, "el primer principio para evitar las manipulaciones que se originan por el mundo de la imagen, icónico-verbal o icónico-sonora, es considerar que los medios no reflejan la realidad, sino una mediación de la misma" (Cabero y Loscertales, 1997, 80) ${ }^{5}$.

La escuela para evitar la uniformización de los sujetos, el deterioro de la cultura y, en definitiva, el control y la manipulación, lo que debe hacer es formar personas críticas, seleccionar la información y reflexionar sobre los medios. Es decir, frente al poder de los medios tanto en los temas de los que se habla, como la definición de lo que se termina por conocer como "normal", los agentes educativos han

5. Esta idea se ve reflejada en el hecho de que la propiedad de los medios de comunicación cada vez está en menos manos. El número de personas que tienen derecho a escuchar y a mirar aumenta constantemente, sin embargo, el número de quienes tienen el privilegio de informar, de crear y de expresarse es cada vez menor. En los últimos años la variedad de canales de radio, de televisión y la misma prensa escrita se ha visto incrementada, si bien al haberse reducido por agruparse los dueños no se ha incrementado realmente. El volumen de grupos mediáticos está decreciendo cada nuevo año como resultado de las fusiones y alianzas. Esta concentración en gigantes mediáticos lleva a una convergencia de contenidos —información y entretenimiento- y tecnologías —el mismo contenido alimenta de forma simultánea a la prensa escrita, al sector audiovisual y a Internet--. "La dictadura de la palabra única y de la imagen única impone por todas partes un mismo modo de vida y concede el título de ciudadano ejemplar a aquel que es consumidor dócil, espectador pasivo, fabricado en serie, a escala planetaria” (GALEANO, 1996, 16). 
de estudiar los medios para hacer comprender a los individuos que en una sociedad democrática puede y debe haber desacuerdos. Ello se consigue formando personas capaces de no tener miedo a preguntarse quién controla los diferentes aspectos de nuestra existencia y cómo esta propiedad encuentra su definición en una comprensión activa de los mensajes transmitidos por los medios.

Por otro lado, desde un punto de vista mental, no producen los mismos efectos sensoriales y mentales las imágenes que las palabras, porque le imponen actividades y procesos distintos. No hay que realizar las mismas operaciones mentales para decodificar textos escritos que para decodificar mensajes audiovisuales. Mientras que los primeros exigen complejas operaciones analíticas, la decodificación de las imágenes es prácticamente inmediata. Cada medio requiere y activa un proceso mental diferente, cada medio lleva a desarrollar habilidades mentales específicas. De esta manera, cada vez que una persona recibe y asimila una información, un contenido o un relato, está poniendo en práctica procesos mentales requeridos para extraer el significado de aquello que ese medio en particular le brinda. Cada medio con la utilización sistemática de unas formas más o menos concretas o abstractas de representación y transmisión de contenidos habituales, predispone a procesar la información de cierta forma e influye en la información que se asimila, condicionando las técnicas y estilos de producción con las que acabarán familiarizándose. Cabe recordar que es clave en la influencia de los mensajes la recepción del lector, el oyente, el telespectador o el internauta.

En este proceso de interacción entre los medios poderosos y la infinitud formativa y de desarrollo del sujeto, el impacto, efectos o consecuencias negativas o positivas que los medios ejercen sobre las personas no se dan sin más, pues si la persona no incorpora la información que llega tal cual de los medios sino que toma un papel activo en su relación con los mismos, esos efectos no tienen por qué ser negativos en la medida en que el sujeto establezca algún tipo de filtro de lo que le llega y, de ello, selecciona lo que le interesa y lo interpreta según sus propios esquemas mentales. Esto supone que la persona deja de ser un consumidor pasivo y se convierte en un protagonista de la acción de los medios sobre sí mismo ${ }^{6}$. Es cierto que al niño o a la niña se le abren o se le cierran perspectivas cognitivas, axiológicas, afectivas, de relación y de acción material y social, por la información que se le brinda o se le niega así como por la forma en que se le ofrece esa información. De la misma manera se le está determinando por el desempeño existencial que le resulte accesible (Martín Serrano, 2000).

Y, en último término, desde una perspectiva cultural, analizando el binomio sujeto-medios, cabría señalar como efecto de la influencia mediática el hecho de generar hábitos cognitivos y perceptivos que inciden en la forma de pensar y

6. Son muchas las aportaciones teóricas sobre el papel que desempeña el sujeto en la relación con los medios. En esta línea, GARCía MADRigal (1996) destaca algunas como: teoría hipodérmica, teoría de los usos y gratificaciones, teoría de la fijación de la agenda y la teoría de la espiral de silencio. 
aprender, y cómo al transmitir una visión fragmentada de la realidad acaban configurando una realidad muy fragmentada, una cultura de tipo mosaico, resultando "una forma de manipular la memoria, y como sabemos, una manera de manipular las relaciones sociales" (Muntañola, 2000, 153). Parece que esta influencia es sensiblemente menor a mayor nivel cultural y formación personal, de manera que el profesor debe encargarse de dar coherencia a los fragmentos de información que proporcionan los medios, de integrarlos en un contexto, de conferirles direccionalidad y sentido en el marco del proceso de enseñanza-aprendizaje.

Ahora bien, ningún efecto actúa de manera automática e inapelable, no es directa la interacción medio-sujeto, sino que están condicionados por una serie de variables y factores interaccionados como la identidad del destinatario, su actitud ante el medio o ante los contenidos y su entorno social, y el contexto donde la interacción sujeto-medio se produzca. Su actitud será distinta en función de sus experiencias previas y de su preparación cultural, de su capacidad crítica, de su sentido reflexivo, etc. ${ }^{7}$. Los medios ejercen influencia efectivamente, pero mediatizada por intereses y otros factores personales. El auténtico mensaje es el resultado de la interacción de factores como el propio destinatario del mensaje, el entorno social en el que se mueve y el contexto comunicativo inmediato. En definitiva, los medios producen efectos, pero no sólo de forma mecánica como en un principio se pensó; no existe el receptor de medios de comunicación como individuo aislado, sin contexto y anclaje en la realidad, sino más bien, incorporado en la potencialidad educativa que exponen los espacios de referencia, considerados no sólo como escenarios físicos sino como contextos o ambientes de convivencia, de interacción, de saber, de producción de conocimiento, como guía para el desarrollo de la personalidad y como base para la formación de actitudes y valores en los medios.

Hay que tener pues cuidado al enseñar a las personas a consumir los medios, pues, si bien nuestra intención debería ser desarrollar su identidad personal y su capacidad comunicativa y expresiva, podemos caer en que al enseñar a consumir los medios les estemos convirtiendo en consumidores dóciles y espectadores pasivos. Es importante dotar a los alumnos, a las personas, de estrategias que les permitan hacer un consumo reflexivo de los medios de comunicación, y que de esta manera puedan descubrir que detrás de un editorial de prensa, detrás de un programa de radio o bien de un programa de televisión, existe toda una lucha por la audiencia, que se manejan las imágenes para crear necesidades.

Por todo esto, es fundamental la enseñanza de estrategias que ayuden a consumir los medios, y más, cuando nos encontramos en una sociedad actual caracterizada por la avalancha de información y la sucesión de cambios. Como apunta González Yuste (2000) tenemos que ir hacia una nueva alfabetización en sentido

7. "Se ha puesto de manifiesto en diferentes estudios que el interés y la actitud de los receptores hacia los medios concretos de comunicación, son determinantes y mediadores, entre la recepción y la exposición al medio por parte del sujeto y la respuesta, o efecto, que se consiga" (CABEro, 1998, 97). 
amplio, que desarrolle una adecuada formación en valores críticos y reflexivos y potencie estrategias de acceso a la información individual y grupal, desarrollando un sentido autónomo de la educación, ayudándoles a comprender el mundo y su mundo, su cultura y su relación con esa cultura, lo que les gusta y lo que no les gusta, llevándoles a pensar lo que puede y debe ser la igualdad y la equidad. Es decir, aportar herramientas para pensar críticamente la realidad y su realidad inmediata y no prohibir sin formación alguna ciertos mensajes.

Un medio de comunicación cualquiera, desde la prensa escrita hasta Internet, es una representación moral del mundo. Por lo tanto, en dicha representación, están mezclados valores que pueden ser considerados educativos y otros que no. No conviene que el niño o la niña tenga acceso solamente a la parte formativa de la realidad. Lo que conviene es que aprenda, tan rápido como sea posible, a distinguir las consecuencias de escoger unos valores u otros. En este sentido, es preciso meditar sin histerismos sobre la conveniencia de vetar, mediante contraseñas, el acceso a determinadas webs de Internet, o la prohibición más habitual de visionar determinados programas de televisión por su contenido. Una prohibición expresa puede no ser más que una forma de focalización y una manera de anticipar o dramatizar los problemas (Espada, 1999, 235).

Ante este panorama global y general, buscando concretar y materializar estas ideas en un medio, a la hora de destacar alguno por su uso y nivel de consumo sin ninguna duda nos detendríamos en la televisión, que se ha convertido no sólo en un miembro más de la familia que habita en el mismo hogar, sino más aun, ateniéndonos a la tesis defendida por Ferrés (1994), en un instrumento básico e importante transmisor cultural. Es en estos momentos un significativo agente social y educativo, relevante instrumento de formación de mentes y conciencias y medio transmisor de valores e ideologías. Además, si tenemos en cuenta que una buena parte de los conocimientos de los jóvenes proviene de lo que han contemplado en la pequeña pantalla, la enseñanza en el aula saldrá beneficiada por el hecho de conectar con los conocimientos e intereses televisivos de los alumnos. E incluso, si se sitúan las imágenes televisivas en un contexto crítico, llevarán a los alumnos a adoptar estas actitudes cuando, fuera del aula, se enfrenten con imágenes similares, de manera que se potencia el aprendizaje en el aula, por motivación y, fuera de ella, por prolongación de las actitudes reflexivas y críticas.

Lo anteriormente comentado nos lleva a una conclusión: es necesario educar para la televisión, pero no sólo educar para la televisión, sino educar con la televisión, es decir, no sólo basta educar acerca de los elementos que configuran la televisión de sus posibles efectos positivos y negativos que puedan producir o cómo hay que seleccionar los programas, etc., sino que es necesario introducirla en los procesos educativos de enseñanza-aprendizaje, en la propia escuela como un recurso didáctico con una gran capacidad de formación a la vez que generadora de gran interés y motivación (Cabero y Loscertales, 1997). El hecho de aprender se llega a asociar con otros escenarios y es en estos escenarios donde la televisión y 
otros medios sí que pueden ejercer un papel. De manera que es la televisión la que debe ser llevada a la escuela y no al revés.

Por tanto, a modo de corolario, todo cuanto hemos dicho sobre el papel y el consumo de los medios de comunicación termina adquiriendo pleno sentido en torno al proceso de socialización. Dentro de la complejidad de la sociedad humana, los medios de comunicación configuran un nuevo elemento formativo de creación de hábitos y costumbres, expectativas sociales y culturales, pautas de comportamiento, medios que han establecido nuevas metodologías de influencia y nuevas formas de presencia social. Como bien observa Marín y Loscertales (2001), ante esta nueva forma de presencia lo que es indudable es que los procesos de socialización ya no son los mismos de antes y que las nuevas generaciones serán claramente influidas y configuradas por este nuevo elemento formativo.

En el proceso de formación humana, junto a instancias y agentes de socialización tradicionales como la familia y la escuela e incluso el grupo de iguales, debemos tener en cuenta el importante papel que juegan los medios de comunicación, pues la persona en formación se ve sometida a las influencias sociales procedentes de los medios, que con más o menos formalidad inciden sobre los sujetos proporcionándoles elementos de formación e información que le facilitan y complementan su proceso de socialización. Influencia e impacto que en el caso de los menores se produce por varias vías, una directa a través del propio menor, y otra indirecta a través de la influencia que los medios ejercen en el entorno familiar, escolar y grupos de amigos.

Hoy se considera que han adquirido una fuerte eficacia socializadora los diferentes medios de comunicación debido a que están produciendo un modelo de educación, de valores, de pautas de comportamiento, de aspiraciones personales y colectivas. Tal vez una de las razones hay que buscarla en la penetración, la presencia activa e influyente que han logrado dentro de la vida privada, por la ilusión de libertad que producen, por la variedad de sus programas, por las fuerzas psicológicas que logran movilizar o por su carácter permanente, pues su influencia se extiende sobre toda la vida (Bartolomé y Sevillano, 1991). De hecho, los medios de comunicación ejercen en nuestra sociedad una potente e importante función en la transmisión de valores sociales y educativos, reflejan y ofrecen formas, modelos de vida y actitudes. Nos pueden imponer modas, consolidar valores o transformar normas de conducta. Lo anterior se comprueba si nos detenemos brevemente en alguno de los valores que han promocionado como por ejemplo los valores democráticos o la denuncia de violaciones de derechos humanos o la divulgación de los avances científicos o potenciar la solidaridad hacia los pueblos que han sufrido una catástrofe. Por sólo estas características se explica el interés desde una perspectiva pedagógica. 


\section{LA CO-RESPONSABILIDAD PARA UNA FORMACIÓN CRÍTICA EN EL USO DE LOS MEDIOS}

Junto al rol que ejercen los medios como agentes socializadores, si hubiera que destacar alguna característica de los medios de comunicación en este principio del siglo xxi ésa sería, sin lugar a dudas, la facilidad con la que han roto las concreciones espacio-temporales; es decir, llegan a cualquier lugar y en cualquier momento. Los diferentes medios y sobre todo la radio y la televisión y últimamente Internet hacen posible que la labor de la escuela tradicional pueda llevarse más lejos que los límites físicos del edificio escolar, variable espacio, entre otras variables, que caracteriza a la educación en la sociedad industrializada. Hoy en la sociedad de la información y de la comunicación, la enseñanza-aprendizaje se caracteriza por la no necesidad de un espacio concreto. Las tecnologías de la información y la comunicación están dando lugar a un nuevo panorama de la enseñanza que puede caracterizarse por la flexibilidad, en el sentido de que desaparecen las limitaciones de tiempo, espacio y apertura, a la vez que nos permite establecer contactos y colaboración con cualquier parte del mundo, con una amplia gama de individuos, tanto fuera como dentro del ámbito educativo. Revolución de las relaciones espacio-temporales que propician ventajas considerables para la enseñanza con su rapidez, pero que a su vez nos debe poner en alerta porque corremos el riesgo de que con el ritmo y la velocidad con que se desarrollan las nuevas tecnologías, los individuos seguramente aprendan inmejorablemente el uso de esos medios pero sin desarrollar el espíritu crítico en relación a las nuevas tecnologías, lo cual conlleva una traslación al resto de medios que tradicionalmente han estado entre sus manos.

De igual modo, gracias a estos cambios espacio-temporales, no es difícil percatarse que los medios de comunicación nos están dando a conocer múltiples horizontes culturales; nos han hecho más patente el paso del tiempo y han contribuido a difundir ideales de vida, concepciones del hombre, cambios de moda, etc. En definitiva, nos han hecho patente el devenir imparable de la vida. Sin embargo, una de las consecuencias con mayor impacto de estos avances ha sido la expansión de un pensamiento único asumido que conlleva a una homogeneización de la cultura, resultando una concentración de poder, de producción y, lo que es más importante, de comunicación. Ésta es una situación contra la que, naturalmente, podemos y debemos rebelarnos los educadores y la sociedad en general. Los medios de comunicación son hoy los principales propagadores del pensamiento único del que ellos mismos son víctimas. En consecuencia, no podemos olvidar los riesgos del poder mediático, según la gráfica definición de Umberto Eco: "La civilización democrática se salvará únicamente si hace del lenguaje de la imagen una provocación a la reflexión crítica, no una invitación a la hipnosis" $(1993,332)^{8}$.

8. Éste es un aspecto que resalta Girardi desde la perspectiva de la globalización, considerando que el aspecto más profundo e inquietante de la dominación que ejerce la globalización es el que penetra en la vida íntima de las personas y pueblos, influyendo en la generalización de unos determinados 
En este sentido, quizás el uso crítico de los medios, la actividad crítica es la única manera para evitar una pasiva homogeneización de los individuos por parte de los medios. Hay que enseñarles a pensar, a hacer, a convivir y a ser; hay que cargar de contenidos críticos el aprendizaje. Creemos que hay que potenciar y desarrollar una formación en medios, y que «educar para formar audiencias conscientes que sepan decidir libremente qué contenidos le son relevantes y adecuados, debería ser una de las finalidades que ayuden a la educación a recobrar el papel relevante y ontológico que siempre ha tenido para la sociedad" (Ballesta y Guardiola, 2001, 119). Es más, el consumo de los medios de comunicación hay que hacerlo de tal forma que se convierta en una relación fértil y constructiva, basada en criterios pedagógicos y educativos, seleccionando aquello que nos pueda ser útil y que nos sirva para nuestra formación y aumento de nuestros conocimientos.

Se trata de buscar procedimientos que permitan a nuestros alumnos desarrollar su autonomía, lo que significa ofrecer formas de pensar, reflexionar y criticar los medios, extrapolables a cualquier otra experiencia audiovisual. Tal y como dice Krasny Brown (1991), los niños dedican hoy día una gran cantidad de su tiempo a ver y escuchar lo que dicen los medios de comunicación, no teniendo criterios de selección que les indiquen qué es lo que deben ver o escuchar y qué es lo que no. Esto significa que no tenemos que quedarnos en preguntas que giran en torno a ia quién le corresponde el educar a los niños acerca del uso de los medios de comunicación?, sino más bien, plantearnos interrogantes como ¿de qué modo debería estar orientada la enseñanza y la educación hacia una práctica que desarrolle sujetos críticos?; o, dicho de otro modo, ¿qué tipo de ciudadanos, alumnos, consumidores y receptores de medios deseamos formar?

Así las cosas, la educación es el mejor instrumento para formar personas reflexivas y críticas ante los medios, pero esta tarea no debe limitarse al contexto escolar. Ésta es una labor que corresponde a todos los agentes educativos que participan en alguna medida en la formación y la enseñanza del niño. Desde los propios padres, involucrando por tanto a la familia, hasta las instituciones sociales pasando lógicamente por la escuela. En muchas ocasiones comprobamos que los medios se convierten en un fenómeno sociológico que impregna la vida cotidiana de las personas y de la sociedad y que genera una cierta coparticipación y, sobre todo, corresponsabilidad. Ello es reforzado por la idea de que los medios no son buenos ni malos, sino que el resultado de los mismos dependerá del uso y de las actitudes de las diferentes personas ante ellos, pues, si bien es posible que los distintos medios fomenten diferentes procesos psicológicos y sociales en sus públicos

\footnotetext{
valores, prolongando la homologación de los espíritus y destruyendo su originalidad e identidad, lo que podría denominarse como "globalización cultural", cuya máxima expresión es la expropiación cultural que se experimenta mediante la interiorización y aceptación del dogma del pensamiento único como "normal" y cuyo rasgo principal es que se mantiene oculta porque penetra no sólo la conciencia, sino también el inconsciente colectivo sentido como algo colectivo inevitable y que no se puede hacer nada para controlar sus efectos sociales (GIRARDI, 1997).
} 
respectivos, sin duda alguna, más que el medio de comunicación en sí, es el contexto social y el uso que se haga del mismo lo que determina el efecto que éste causa sobre el pensamiento.

Dentro de este contexto social co-responsable de la formación en los medios, la familia ocupa un lugar de preeminencia, precisamente por estar situada en lo que es el contexto social inmediato y cotidiano?. Sin duda esta labor de trabajo con los medios no podrá realizarse con éxito sin el empeño y la participación de las familias; en consecuencia, desde los centros de enseñanza "se ha de informar a los padres de la importancia que el profesor concede al papel educativo de los medios de comunicación de masas en la vida de sus hijos y la responsabilidad de la familia en cuanto a orientar a los niños en el uso adecuado de los mismos" (Tyner y Lloyd, 1995, 21), sobreentendiendo que la labor de educar para los medios no debe ser sólo una responsabilidad que deba cumplirse en el ámbito escolar, pues enseñar a los niños a utilizar los medios y todos los sistemas de transmisión del conocimiento no sólo es tarea del profesor, sino que alcanza también a los padres.

Junto a la familia, nadie pone en duda que otro de los agentes que, en mayor o menor medida, más influye en el desarrollo de la formación de sujetos críticos ante los medios son los profesores. La escuela considerada como un sistema dentro de nuestro sistema social no puede ser ajena a los nuevos medios y en concreto a las nuevas tecnologías de la información y de la comunicación que están surgiendo. Nuevas tecnologías que son un elemento importante de nuestro entorno cultural, económico y social y a las que la escuela debe responder para así dar salida a uno de sus objetivos como es el de preparar personas capaces de vivir y de integrarse en la sociedad. Como aprecia Rodríguez Diéguez (1995) el oponerse a la tecnología puede ser debido más a un desconocimiento de su utilización y aplicaciones que a una oposición fundamentada y seria de sus limitaciones y consecuencias.

Ahora bien, en lo que no terminamos de estar todos de acuerdo es en la formación del profesorado ante los medios. Cabe una pregunta: ¿conoce el docente la gran cantidad de aspectos que rodean al mundo de los medios de comunicación y que son susceptibles de trabajarse en el aula? Pensamos que sigue siendo necesaria un reflexión acerca del vacío de formación entre los profesores sobre la alfabetización audiovisual, el uso didáctico de los medios de comunicación y su integración plena y real en el currículum. El profesorado requiere una formación adecuada y continua, no sólo orientada al uso de los medios por parte del profesor. Hay que formar al docente para que enseñe a sus alumnos la verdadera función de los medios y para que los introduzca en la propia aula. El profesor ha de adentrarse en ese mundo en el que el niño ya es partícipe y sacarle el mayor rendimiento posible. Está claro que previo a esto el profesor debe conocer "qué

9. Es destacable el impacto que han ejercido los medios de comunicación en el ámbito familiar, efectos que Morales (1996) describe en su artículo «La influencia de los medios de comunicación en la vida de la familia". 
mecanismos ha de poner en marcha, criterios a seguir, qué funciones ha de adquirir, etc.". Pensamos que sería conveniente formar al profesorado en estrategias de investigación, de selección y adaptación de los materiales audiovisuales y tecnológicos que nos proporciona el entorno.

$\mathrm{Y}$, en último término, junto a la escuela y a los profesores, los padres y las familias, no debemos olvidarnos del potencial educativo que tienen los propios espacios socioculturales que son quienes terminan de dar sentido a las transacciones que se realizan entre los individuos y los medios. Cualquier ciencia que estudia, entre otros aspectos, el comportamiento de los sujetos ante los medios de comunicación, no puede ocuparse solamente de intercambios sociales y comunicativos entre individuos. Éstos, además de enviar mensajes entre ellos con un grado mayor o menor de intencionalidad, son en sí mismos un mensaje elaborado y construido a la vez por los mensajes que reciben del espacio sociocultural, del ambiente y no sólo de los individuos. Así evitamos reducir la cuestión de la formación crítica de los medios a palabras y descubrimos el potencial formativo de los espacios, los procesos por los que el entorno, componente situacional, es agente de inducción de comportamientos críticos (García del Dujo y Muñoz Rodríguez, 2001).

Pues bien, a partir de este contexto formativo, cabe señalar objetivos y estrategias a utilizar para formar a personas reflexivas y críticas ante los medios y para hacer un mejor consumo de los mismos. Una de las mayores preocupaciones es desarrollar la competencia necesaria que posibilite el control sobre el uso que los individuos hacen de los medios. Si a los menores se les inculcan las pautas críticas adecuadas para enfrentarse a los medios, comenzarán a tomar decisiones sobre lo que ven, lo que leen o lo que oyen en lugar de ser lo suyo una acción pasiva. Se trataría de efectuar competencias comunicacionales pragmáticas, de cara a la acción educativa, donde se rompe con la idea tradicional de mera transmisión y pasamos a concebirla como proceso creativo en el que participan múltiples mensajes desde diversos ámbitos situacionales, dando cabida a aspectos relacionales, de contenido y circunstanciales. De este modo, la comunicación que se termina estableciendo entre los medios y los individuos deja de ser un medio para ser, además, un valor, lo cual redundará en un uso crítico.

Hay que enseñarles a reflexionar sobre lo que nos transmiten, a descubrir el fundamento último de los medios; hay que aprender a desvelar sus intenciones, enseñándoles a entender su lenguaje e incluso posibilitar el uso de soportes técnicos para que conozcan sus posibilidades de manejo a la vez que se debe desarrollar la competencia de que sean ellos mismos los que tomen las decisiones sobre sus necesidades y el modo de satisfacerlas. Ello implica una enseñanza a los alumnos en cuanto que modos de acceder a mensajes, descifrar tramas semióticas, analizar mensajes, evaluar mensajes y comunicar mensajes, en el sentido de dotar a los alumnos de capacidades de expresión, selección de códigos, utilización de recursos, etc.

Es importante despertar el sentido crítico en niños, jóvenes y mayores, para que podamos utilizar los medios como vehículo de educación y cultura, además de 
entretenimiento, sin olvidar que los medios no sólo transmiten información, sino que crean opinión, pues los mensajes, además de construirse con el objetivo de sensibilizar a los receptores, tienen propósitos, en muchos casos, económicos, ideológicos y políticos que trascienden la capacidad crítica de los alumnos y que nos obligan a nosotros a educar en la comprensión y desciframiento de los contenidos pues, como escribe Tyner:

Los peligros de no analizar el contenido de los medios de comunicación son aún mayores para los niños, por encontrarse éstos entre la audiencia más numerosa pero menos sofisticada de la sociedad. Si fracasamos en ayudarles a adquirir una formación audiovisual que les permita analizar de forma crítica lo que ven y más tarde lean, contribuiremos a que desarrollen visiones de sí mismos controladas por personas ajenas a ellos y a nosotros mismos cuyos valores y visiones podemos o no comprender $(1995,15)$.

Junto a este análisis de los contenidos, hemos de insistir en el hecho de que el contenido de los medios no es real, es decir, que todos los mensajes de los medios son realidades elaboradas, que alguien ha creado el mensaje, lo ha seleccionado, lo ha producido y ha instrumentalizado su presentación para mostrarlo a la audiencia (naturaleza prefabricada del contenido). La realidad que presentan es un tipo de realidad transformada cultural y simbólicamente, una transformación vicaria de la realidad. Los medios deberían ser el reflejo de la realidad, pero no siempre es tan fiel la información que presentan como sería deseable; de ahí que insistamos en la importancia que tiene formar personas críticas y capaces de tener una postura de análisis ante la información que nos proporcionan. Por tanto, comprender cómo los mensajes de los medios afectan nuestra visión del mundo es central para una alfabetización y formación en los medios.

Podríamos desarrollar estrategias más concretas relativas a cada uno de los medios, pero si nos planteamos - pretendemos- que los niños reflexionen críticamente sobre la influencia de los medios y los utilicen de forma adecuada, siendo selectivos con la información que reciben, habrá que proporcionarles estrategias generales que les harán cuestionarse cosas que por sí solos no se cuestionarían, y es que los distintos medios de comunicación lo que hacen es evitar el desarrollo de posicionamientos críticos hacia la sociedad al transmitir modelos y pautas de comportamiento uniformadoras. Es decir, para una educación en los medios es fundamental implementar en los individuos una confianza suficiente en sí mismos que les capacite para desarrollar una madurez crítica que a su vez les permita plantear juicios reflexivos respecto de los mensajes que provienen de los medios de manera autónoma ${ }^{10}$.

10. "El interés del pedagogo por el sujeto se centra en aportar contenidos de conciencia y en favorecer el posicionamiento del sujeto respecto a esos contenidos; en última instancia, la ontología de los procesos educacionales viene dada por el sistema de sucesos en la subjetividad y la pedagogía queda constituida por el sistema de acciones que pretenden favorecer acontecimientos en la subjetividad". (García Carrasco y García del Dujo, 2001, 62). 
Por tanto, la sola adquisición de conocimientos no es suficiente. Hemos de educar en el tratamiento de la información y no sólo a memorizarla, buscando que los individuos, alumnos principalmente, sean no sólo capaces de analizar sino también de comunicarla. En consecuencia, estamos convencidos de que

educar en los medios no es sólo fortalecer la comprensión crítica de los medios sino, especialmente, la autonomía crítica respecto de ellos [...]. Dicho de otro modo, no es posible hablar de una verdadera educación en medios si esta enseñanza no se inscribe en el marco de un enfoque pedagógico que fortalezca las habilidades críticas del alumno en su propia relación con los medios de comunicación (Piette, 2003, 131).

Es evidente que no nos situamos en una postura negativa ante los medios; más bien, hemos de reconocer que son muchas las ventajas que se derivan del hecho de trabajar educativamente con ellos además de fomentar la conciencia crítica como son el trabajo en equipo, el respetar las opiniones de los otros, la creatividad, la autoestima, etc.

\section{HaCIA UN DiÁlOGO CONSTANTE ENTRE LOS MEDIOS Y LA EDUCACIÓN}

Este espíritu y pensamiento crítico que demandamos y necesitamos forjar en los individuos como epicentro del fenómeno formativo en los medios de comunicación, necesita a su vez un replanteamiento y recomposición de las tramas que conectan el mundo de los medios con el mundo de la educación. De este modo, más que hablar de conflictos entre educación y comunicación, entre enseñanza y medios de comunicación, debemos centrarnos positivamente en la complementariedad y la posibilidad de cooperación e interdependencia. La escuela tiene que abrirse a la idea de que no es ya ella sola el gran centro de información y debe atender al innumerable aporte que los medios puedan servirle. Es adecuado reconocer que los medios comportan un gran potencial tecnológico de información, de ocio y de comunicación y en la medida en que nos permitan más cosas, contribuyen a enriquecer la persona, aunque, conviene igualmente tener en cuenta que "la mayor presencia de medios en los centros, si no concurren otras variables, no tiene por qué repercutir en una mejora del acto didáctico y en un aumento cuantitativo y cualitativo de los aprendizajes" (Cabero, 1992, 64).

El contexto social actual caracterizado por el predominio de la cultura audiovisual, masivamente apoyado en la imagen, nos impone un cambio, un acercamiento no sólo al lenguaje verbal sino también al lenguaje no verbal, principalmente al de la imagen. En un entorno comunicativo preferentemente icónico, debemos enseñar a usar los medios para evitar que la imagen nos manipule. La escuela, por lo general, favorece un tipo de lenguaje, incluso privilegia la enseñanza del lenguaje verbal, descuidando otras formas de comunicación. No se ocupa apenas del lenguaje de las imágenes y no estaría de más reconocer que hasta ahora los medios audiovisuales no 
son usos significativos y suelen identificarse más con una actividad recreativa (Pro, 2003).

Estamos ante una de las disociaciones más fuertes, entre el ámbito escolar y el entorno social donde se desarrolla. Como llama la atención Ferrés (1995), la hegemonía de la imagen en las sociedades occidentales desarrolladas contrasta con su escasa presencia en el ámbito escolar. El sistema educativo se encuentra con un nuevo alumno que se ha socializado en el mundo de las imágenes y esto exige un replanteamiento en las estrategias educativas. En este nuevo entorno, la educación debería plantearse un nuevo modelo comunicativo; hoy en día se hace necesario un nuevo tipo de alfabetización: el sistema educativo debe alfabetizar en su sentido tradicional y en una alfabetización visual. En una sociedad como la nuestra, donde la imagen, el texto y el sonido tienden a ser asociados cacla vez más, es preciso desarrollar la lectura de imágenes como estrategia eclucativa, lo cual obliga a capacitar a los alumnos para establecer relaciones entre un contenido y su expresión; supone, como establece Lomas (1992), una cualificación para observar los signos mínimos que configuran una imagen así como las relaciones establecidas entre ellos y, en consecuencia, una clara conciencia de las estrategias discursivas puestas en juego.

Esta exigencia de un nuevo tipo de alfabetización debe plantear a la vez un modelo comunicativo en el que se privilegie la sensorialidad, la concreción, la emoción, en tanto que medios para conectar con los alumnos en una sociedad que vive en una cultura de la persuasión y la seducción pero donde no se forma en el ámbito de esa influencia social, es decir, se educa sólo en la racionalidad mientras en el entorno se priva la emotividad. Se trata de dar cabida al sentimiento, ese gran ausente en muchos de los procesos formativos, principalmente formales y, sobre todo, en los tramos superiores del sistema de enseñanza, porque, el afecto se puede mostrar pero no enseñar, intuir, pero casi nunca instruir; es algo clifícil de aprender. $Y$, sin embargo, comprobado está que forma parte de los procesos educativos como base misma, como elemento intrínseco a su formulación, como elemento decisivo en la configuración de la personalidad de los sujetos y de su desarrollo no sólo afectivo, sino también conductual y cognitivo. Porque, si algo tiene la afectividad en relación a la educación en los medios es que no es sólo padecida, sino también comunicada, por medio de un lenguaje compartido que es el que hemos de descifrar y al que debemos dar cabida a partir de una estructura o trama comunicativo-afectiva.

Vivimos en un mundo de poclerosas imágenes, palabras y sonidos y tenemos que aprender y enseñar cuanto antes a cribarlos, interpretarlos y clarles un sentido. Hoy en día, nos ha tocado vivir en una época en la que los símbolos, aquellos elementos que comportan múltiples significados, cargados de historia, que otorgan sentido pleno a los objetos y las acciones, que contienen en su seno un trozo de la experiencia de la vida de las personas, vienen impresos y definidos por una velocidad que los hace pasar uno tras de otro ante las vidas de los sujetos, no dando tiempo a mostrar su significado (Fernández Christlieb, 2000). Hay que dotar a las 
personas de la habilidad para seleccionar, interpretar, cuestionar y dar un sentido a los estímulos y significados que nos llegan diariamente a través de la televisión, radio, prensa, Internet.

Educar con los medios y para el uso y consumo de los medios se propone pasar de ser destinatarios de mensajes a usuarios e intérpretes, auténticos partícipes personales de la comunicación. Hay que hacerles comprender a los sujetos la diferencia entre lo real y lo imaginario, entre la realidad y la realidad que los medios nos ofrecen. En términos globales, los medios representan un fenómeno positivo como cualquier otra forma de desarrollo. Pero la sola presencia de los medios no lleva sin más a consecuencias positivas o negativas, ni a una utilización correcta o irresponsable. Los medios de comunicación son precisamente eso, medios y como ha sucedido con los demás instrumentos que se han dado en el desarrollo de la humanidad, donde hay que centrarse es tanto en la utilización y responsabilidad de los mismos como en la interpretación de sus mensajes, exigencia de mayor responsabilidad que la sociedad demanda de los medios ${ }^{11}$.

Conviene pues introducir desde edad temprana el aprender a interpretar los lenguajes de los medios para adoptar una postura crítica y consciente ante sus mensajes, y no dejarse manipular con resignación, ingenuamente o con pasividad por todo lo que vemos, leemos o escuchamos. Hay que fomentar y desarrollar capacidades que nos permitan enseñar a digerir la información y convertirla en conocimiento. Resulta pertinente, por tanto, establecer los procesos formativos en base a una serie de principios que ayuden a las personas a descifrar el significado de los medios con los que comparten sus vidas. Para formar al sujeto en los medios, necesitamos interpretar cómo sus actos y relaciones están moldeados, en parte, por el significado que evocan y tienen los medios con los que interrelaciona, lo cual nos indica una propiedad a tener en consideración cual es la de que, si queremos presentar acciones e intervenciones educativas en los medios, hemos de analizar el modo en que los sujetos participan de las tramas o sistemas simbólicos y semióticos de que gozan esos medios ${ }^{12}$.

Para satisfacer estas nuevas demandas afectivas, de significación y de hermenéutica que van surgiendo, la educación tiene que ser más flexible, adaptarse a las necesidades de los usuarios y aumentar la calidad del aprendizaje. Los progresos en medios de comunicación y en las tecnologías de la información deben ser utilizados en educación como ayuda para conseguir tal adaptación a las nuevas realidades del

11. Subrayado en su día con claridad por Núnez Encabo: "Existe la tentatica cada vez más frecuente de tratar la información como una mera mercancía. El objetio principal seria llegar al mayor número de público para obtener los máximos ingresos por publicidad... El peligro que de ello se deriva es considerar a los ciudadanos no como tales sino como masa. sustituyendo al concepto de público por el de cliente" (Ni cirz, 1995, 260).

12. El significado simbólico. por tanto, depende críticamente de la capacidad humana pará internalizar ese lenguaje y usar su sistema de signos como interpretante de estals relaciones de "representación" (BRL Ylik. 1991. 77). 
contexto sociocultural. Una de las tareas de la educación es desarrollar la aptitud del alumno para evaluar de manera crítica el ámbito en el que vive, ámbito en el que los medios de comunicación representan un papel importante.

Es por eso necesario desarrollar todas las capacidades en los alumnos para ponerlos en posibilidad de adaptarse y hacia una integración en una sociedad en evolución, preparándoles para un consumo selectivo de los medios y sus informaciones (Bartolomé y Sevillano, 1991). La adaptación al medio ambiente no puede ser, en nuestros días, una adaptación pasiva en la que fundamentalmente se adquiere la capacidad de consumir información. Se trata más bien de saber discernir el "para qué" de ese consumo. Un primer paso para la consecución de este propósito es la desmitificación de los medios, desmitificación que sólo se obtiene mediante la educación y el desarrollo del sentido crítico. El conocimiento funcional, el conocimiento operativo de los medios, así como el acceso a su manejo pueden ser dos vías de indudable interés (Roda Salinas y Beltrán de Tena, 1992).

Defendemos el diálogo y la utilización de los medios de comunicación en la enseñanza y en el mundo de la educación en general por la influencia, como hemos comentado, que tienen en todos los ámbitos de nuestro entorno con sus consecuencias positivas y negativas. Es pues importante que estén presentes en el ámbito educativo para desmitificarlos, comprenderlos, entenderlos, racionalizarlos y utilizarlos más adecuadamente, pero también como medio de apertura sobre el mundo circundante a la escuela y a las personas, asumiendo así que los medios son una buena dimensión de la cultura y la sociedad en la que convivimos diariamente, posibilitando a la escuela y al mundo educativo insertarse en los procesos de cambio que atraviesa nuestra sociedad. Creemos necesario un «uso racional y crítico de los medios adecuándolos a las necesidades y exigencias de cada contexto, conociéndolos y sabiendo cuáles son sus posibilidades reales, que realmente son muchas y muy atractivas" (Cabero, 1995, 84).

La relevancia de los medios queda de manifiesto en el hecho de que en cualquiera de nuestros hogares nos podemos encontrar con múltiples manifestaciones de ellos como un periódico, un programa de radio, la televisión, un tebeo, Internet. Estos medios forman parte de nuestra vida y como manifiesta McLuhan (1996) en la era de la comunicación instantánea en la que nos situamos, nuestra supervivencia, nuestra felicidad y confort, nuestro actuar cotidiano, depende de la comprensión de nuestro entorno inmediato, porque este tipo de comunicación ha constituido una total y casi instantánea transformación de la cultura, valores y actitudes.

El mundo educativo deberá incorporar los elementos esenciales de la nueva sociedad de la información, lo cual exige una formación en los medios de comunicación y en los nuevos lenguajes. La red de redes, Internet y sus derivaciones Intranet/Extranet, no sólo se presenta como un nuevo medio de comunicación, como el actual instrumento por excelencia de la recepción, consulta, producción y difusión de información de todo tipo, sino que su presencia en el sistema educativo está configurando un nuevo modelo de formación. El acceso a las tecnologías de la información y la comunicación es cada vez más asequible, aunque es 
importante señalar que las tecnologías anteriores continúan jugando un papel fundamental en la educación. La enseñanza de los medios cada vez está más extendida, hagamos de nuestros alumnos personas más activas, más partícipes y con capacidad de selección, elección y crítica pues estamos convencidos de que la manera más significativa de información y comunicación en nuestras vidas en los próximos años serán los medios, de ahí la necesidad de educar en los medios como fundamento en la construcción del pensamiento crítico de las personas y como ayuda para formar su propia identidad individual y colectiva.

Finalizar nuestra reflexión en relación con la educación y los medios de comunicación destacando uno de los objetivos nucleares en la reforma de la enseñanza como es la formación de actitudes críticas frente a la enorme y diversa información que recibimos por los más variados medios para de esta manera favorecer y lograr alumnos, personas que utilicen los medios conociendo sus implicaciones, posibilidades y limitaciones socioculturales. Ello no significa censurar o condenar los gustos de los alumnos por una determinada información, poniendo en práctica actos de rechazo o de ignorancia hacia los medios, sino que más bien es una actividad de pregunta, de exploración, de cuestionamiento y de compromiso con los medios. Se trata de analizar el medio y el placer que pueden mostrar los sujetos antes de cuestionarlo o elogiarlo.

Por tanto, teniendo en cuenta la influencia de los medios en la sociedad actual, el sistema educativo no sólo debe alcanzar una adecuada formación académica de sus alumnos, sino también una buena formación social como ciudadano, enseñando a las personas a leer ciudadanamente el mundo, integrando en su currículum el conocimiento y utilización de las nuevas técnicas de información y comunicación. De esta manera formará lectores, oyentes y telespectadores, reflexivos, pluralistas, autónomos, participativos y consumidores equilibrados, con mentalidad crítica, cuestionadora y desajustadora de la inercia en la que la gente vive.

\section{BiBLIOGRAFíA}

APARICIO, R. (coord.) (1996) La revolución de los medios audiovisuales. Madrid, Ed. de la Torre.

Ballesta, J. y Guardiola, P. (2001) Escuela, familia y medios de comunicación. Madrid, CCS. Bartolomé, D. y Sevillano, M. ․ L. (1991) Enseñanza-aprendizaje con los medios de comunicación en la reforma. Madrid, Sanz y Torres.

BRown, L. K. (1991) Cómo utilizar bien los medios de comunicación. Madrid, Visor.

Bruner, J. (1991) Actos de significado. Más allá de la revolución cognitiva. Madrid, Alianza.

CABERO, J. (1992) Estrategias para una didáctica de los medios en la escuela, en Grupo PRENSA-Escuela. Enseñar y aprender con prensa, radio y televisión. Huelva, Grupo Prensa-Escuela, 27-32. 
CABERO, J. y LOSCERTAles, F. (eds.) (1998) ¿Cómo nos ven los demás?: La imagen del profesor y la enseñanza en los medios de comunicación social. Sevilla, Universidad de Sevilla.

Cabero, J. y Martínez, F. (1995) Nuevos canales de comunicación en la enseñanza. Madrid, Centro de estudios Ramón Areces.

Cebrián de la SeRna, M. (1992) La didáctica, el currículo, los medios y los recursos didácticos. Málaga, Universidad de Málaga.

Colom, A. J. (2002) La (de) construcción del conocimiento pedagógico. Nuevas perspectivas en Teoría de la Educación. Barcelona, Paidós.

Delors, J. (coord.) (1996) La educación encierra un tesoro. Madrid, Santillana/Unesco.

Dewey, J. (1998) Democracia y Educación. Madrid, Morata.

ECO, U. (1993) Apocalipticos e integrados. Barcelona, Lumen.

EspadA, A. (1999) La educación mediada, en AA.VV. Por una ciudad comprometida con la educación. Barcelona, Ajuntament de Barcelona, Institut d'Educació, 234-241.

FERNÁNDEZ, J. (1998) Contra la ingenuidad mediática, en SOSA, N. M. et al. (coords.). La educación ambiental. 20 años después de Tbilisi. Salamanca, Amarú, 303-308.

Fernández Christlieb, P. (2000) El terrorismo instantáneo de la comunidad postmoderna, en Lindo Fernández, N. A. La vida cotidiana y su espacio-temporalidad. Barcelona, Anthropos, $147-170$.

Fleur, M. L. y Ball-Rokeach, E. J. (1993) Teoría de la comunicación de masas. Barcelona, Paidós.

Fontcuberta, M. de (1992) Medios de comunicación telemática y educación, Revista Comunicación, lenguaje y educación, 14, 18-19

- (2003) La educación fuera de la escuela, en Morduchowicz, R. (coord.). Comunicación, medios y educación. Un debate para la educación en democracia. Barcelona, Octaedro, $51-56$

FERRÉs, J. (1994) Televisión y educación. Barcelona, Paidós.

- (1995): Estrategias para el uso de la televisión, Cuadernos de Pedagogía, 234, 18-21.

Ferrés, J. y Marqués, P. (1996) Comunicación educativa y nuevas tecnologías. Barcelona, Praxis.

GalEano, E. (1996) Vers une société de l'incommunication, en Le Monde Diplomatique, octubre, $502,16$.

García Carrasco, J. y García del Dujo, A. (2001) Teoría de la Educación II. Procesos primarios de formación del pensamiento y la acción. Salamanca, Universidad de Salamanca.

García del Dujo, A. y MuÑoz Rodríguez, J. M. (2001) Dinámicas de (des)estructuración espacial y procesos de configuración individual y social, en XX Seminario Interuniversitario de Teoría de la Educación "Conflicto, Violencia y Educación", Murcia, Universidad de Murcia.

García Madrigal, F. (1996) Influencia y efectos de los medios: la creación de estereotipos sobre la droga, Revista Acciones e investigaciones sociales, 4, 181-199.

GIRARDI, G. (1997) Globalización, cultura educativa y su alternancia popular, Exxodo, 39, 14-27.

González SOTO, A. (1998) Perspectivas de futuro en la utilización de las nuevas tecnologías en la formación ocupacional y de empresa, Píxel-Bit. Revista de Medios y Educación, 10, 7-23.

González Yuste, J. L. (2000) Variables de la eclucación en comunicación, en Pérez Tornero, J. M. Comunicación y educación en la sociedad de la información. Madrid, Paidós. 
JaCQuinot, G. (1993) Saberes escolares y saberes mediáticos: ¿choque o cultura?, en MorduCHowicz, R. (coord.). Comunicación, medios y educación. Un debate para la educación en democracia. Barcelona, Octaedro, 43-50.

LoMAS, C. (1992) La imagen: instrucciones de uso para un itinerario de la mirada, Signos, 1 , $14-27$.

Martín Serrano, M. (2000) La influencia de la televisión en el ser y el hacer de los niños y de las niñas, en AA.VV. La sociedad educadora. Madrid, Fundación Independiente, 247-267.

McluHan, M. (1996) Comprender los medios de comunicación. Barcelona, Paidós.

MARIN, M. y LosCerTAles, F. (2001) Educación, medios de comunicación y formación humana, en Fernández, T. y García, A. (coords.). Medios de comunicación, sociedad y educación. Cuenca, Universidad de Castilla-La Mancha, 33-60.

Mastermar, L. (1993) La enseñanza de los medios de comunicación. Madrid, Ed. de la Torre. MEC (1989) Libro Blanco para la Reforma del Sistema Educativo. Madrid, MEC.

Morales, M. R. (1996) La influencia de los medios de comunicación en la vida de la familia, Cuadernos de Realidades Sociales, 47/48, 187-203.

MORIN, E.; ROGER, E. y MOTTA, R. D. (2002) Educar en la era planetaria: el pensamiento complejo como "Método" de aprendizaje en el error y la incertidumbre bumana. Valladolid, Universidad de Valladolid.

Muntañola Thornberg, J. (2000) El significado de la fragmentación arquitectónica, en ídem Topogénesis. Fundamentos de una nueva arquitectura. Barcelona, UPC, 153-160.

Núñez, M. (1995) Código europeo de deontología del periodismo, en Bonete, E. (coord.). Eticas de la información y deontologias del periodismo. Madrid, Tecnos, 252-279.

PARCERISA, A. (1996) Materiales curriculares. Barcelona, Graó.

PAstor, G.; PINTO, M. ․ R. y ECHEVERRI, A. (coords.) (2000) Cultura y medios de comunicación. Salamanca, Universidad Pontifica de Salamanca.

Pérez González, E. (1995) Transversalidad en los medios de comunicación social, Comunidad Educativa, 228, 24-26.

PIETTE, J. (2003) ¿Qué es un receptor crítico?, en MORDUCHOwICZ, R. (coord.). Comunicación, medios y educación. Un debate para la educación en democracia. Barcelona, Octaedro, 131-138.

Pro, M. (2003) Aprender con imágenes. Incidencia y uso de la imagen en las estrategias de aprendizaje. Barcelona, Paicós.

Roda Salinas, F. J. y Beltrán de Tena, R. (1992) Información y comunicación. Los medios y su aplicación didáctica. Barcelona, Gustavo Gili.

Rodríguez Diéguez, J. L. y SÁEnz BARRio, O. (1995) Tecnología educativa. Nuevas tecnologias aplicadas a la educación. Alcoy, Marfil.

Santos Guerra, M. A (2002) Hacia el futuro: riesgos y esperanzas, en ANaut, L. et al. Valores escolares y educación para la ciudadanía. Barcelona, Graó, 29-32.

Tyner, K. y Lloyd, D. (1995) Aprender con los medios de comunicación. Madrid, Ed. de la Torre.

Zabalza, M. A. (1987) Diseño y desarrollo curricular. Madrid, Narcea. 